\title{
KHẢO SÁT MỨC Độ BIẾN ĐÔI NUCLEOTIDE GEN E6, E7 VÀ L1 CỦA HUMAN PAPILLOMAVIRUS TYPE 16 VÀ 18 Ở BẸNH NHÂN UNG THƯ CỎ TỬ CUNG
}

\author{
Hoàng Xuân Sơn ${ }^{1, \bigotimes}$, Vũ Bá Quyết ${ }^{2}$, Nguyễn Vũ Trung ${ }^{3}$ \\ ${ }^{1}$ Trung tâm Y tế Chợ Mới - Bắc Kạn \\ ²Bệhh viện Phụ sản Trung ương \\ ${ }^{3}$ Trường Đại học Y Hà Nội
}

Trong số các type HPV gây bệnh ở người, type 16 và 18 là hai type có tỷ lệ gây ung thư cổ tử cung rất cao. Các nghiên cứu cho thấy sự biến đổi trình tự nucleotide trong bộ gen của type 16, 18 có thể thúc đẩy tiến triển ung thư cổ tử cung và các triệu chứng khác ở người bệnh. Trong nghiên cứu này, chúng tôi phân tích sự biến đổi trình tự nucleotide trên các gen E6, E7 và L1 của hai type HPV 16 và 18 ở những người bệnh đã được xác định mắc ung thư cổ tử cung. Sàng lọc 104 bệnh nhân, có 63 bệnh nhân đủ tiêu chuẩn lựa chọn vào nghiên cứu, bao gồm 46 trường hợp nhiễm đơn HPV-16 và 17 trường hợp nhiễm đơn HPV-18. Kết quả phân tích trình tự nucleotide của các gen E6, E7, L1 của các type này cho thấy: Type HPV 16 có 13 biến đổi được tìm thấy ở gen E6; tỷ lệ đột biến cao nhất là T350G với 100\%; thấp nhất là A378G 10,9\%. Trên gen E7, vị trí có tỷ lệ đột biến cao nhất là C578T ở với $60,9 \%$ và thấp nhất là $A 739 G$ với $13,0 \%$. Trên gen $L 1$ xác định đượC 40 đột biến, trong đó đột biến G7060A chiếm tỷ lệ cao nhất là 80,4\%. Type HPV 18, ở gen E6 xuất hiện 14 đột biến, tỷ lệ cao nhất là G532T với 41,2\%; Trên gen E7 tìm thấy 6 đột biến, trong đó đột biến C894T và C898T chiếm tỷ lệ 47,1\%; Có 24 đột biến tìm thấy ở gen L1, đột biến cao nhất xuất hiện ở vị trí G5612T với 17,6\%.

Từ khóa: Ung thư cổ tử cung, HPV, đột biến, gen E6, E7, L1.

\section{I. ĐẠT VẤN ĐÊ}

Ung thư cổ tử cung là loại ung thư phổ biến nhất trong số các loại ung thư ác tính ở đường sinh sản nữ. ${ }^{1}$ Dữ liệu dịch tễ học cho thấy nhiễm trùng dai dẳng với Human Papillomavirus (HPV) có thể gây ung thư cổ tử cung, đặc biệt là nhiễm type HPV-16 và $18^{2,3,4}$ Các nghiên cứu cho thấy ung thư cổ tử cung chủ yếu liên quan đến hai type HPV là 16 và $18.5,6$

Dự liệu nghiên cứu cho thấy HPV type 16 và 18 có sự đa dạng di truyền (biến thể - variant), khác biệt $\leq 2 \%$ trình tự hệ gen so với chủng hoang dã và được phân loại thành các nhánh

Tác giả liên hệ: Hoàng Xuân Sơn

Trung tâm Y tế Chợ Mới - Bắc Kạn

Email: xuansonhbb@gmail.com

Ngày nhận: 02/12/2021

Ngày được chấp nhận: 28/12/2021 phát sinh loài (phylogenetic branches). Một số nghiên cứu ghi nhận có sự liên quan giữa các biến thể với sự nhiễm trùng dai dẳng của HPV và sự hình thành các tổn thương ác tính. Một số biến thể được tìm thấy có liên quan tới ung thư cổ tử cung, đặc biệt là một số biến thể mang các đột biến gây ung thư tiềm năng như L83V và D25E (type 16) trên gen E6. ${ }^{7,8}$

Ngoài ra các báo cáo này cũng ghi nhận tỷ lệ và mức độ biến đổi trình tự nucleotide ở gen E6 và $E 7$ có sự khác nhau tùy thuộc vào chủng tộc và vùng địa lý. ${ }^{9-12}$

Tại Việt Nam, cho đến nay có rất ít nghiên cứu về đột biến của các type HPV nguy cơ gây ung thư cổ tử cung cao như HPV16, HPV18. Việc xác định mức độ biến đổi nucleotide ở các gen điều hòa như L1, E6, E7 của HPV sẽ làm 
rõ mối liên quan giữa các đột biến xuất hiện ở HPV 16, 18 với bệnh lý ung thư cổ tử cung, giúp cho nâng cao hiểu biết và tiên lượng mức độ bệnh cũng như nguy cơ tiến triển ung thư cổ tử cung ở những người nhiễm HPV 16, 18 có mang đột biến để từ đó đưa ra những giải pháp sàng lọc, giám sát và điều trị hiệu quả hơn. Vì lý do đó chúng tôi tiến hành thực hiện nghiên cứu này với mục tiêu: xác định tỷ lệ đa hình đơn nucleotide trên gen E6, E7, L1 của các type HPV16 và 18 ở bệnh nhân ung thư cổ tử cung.

\section{II. ĐỐI TƯợNG VÀ PHƯƠNG PHÁP}

\section{1. Đối tượng}

Nghiên cứu được thực hiện trên 63 bệnh nhân có bằng chứng mắc ung thư cổ tử cung đang điều trị tại Bệnh viện Phụ Sản Trung Ương.

\section{Tiêu chuẩn lựa chọn}

Bệnh nhân có kết quả mô bệnh học ung thư cổ tử cung, có kết quả xét nghiệm HPV DNA (+) với các type:

+ Đơn nhiễm HPV 16

+ Đơn nhiễm HPV 18.

- Tiêu chuẩn loại trừ: Không đồng ý tự nguyện tham gia nghiên cứu, đã mổ cắt tử cung hoàn toàn, không có xét nghiệm PCR HPV hoặc có xét nghiệm PCR HPV (-), đồng nhiễm HPV nguy cơ cao.

\section{Thời gian và địa điểm nghiên cứu}

Thời gian nghiên cứu từ tháng 01/2019 đến tháng 03/2020.

Địa điểm: Bệnh viện Phụ sản Trung ương: thu tuyển bệnh nhân ung thư cổ tử cung có kết quả xét nghiệm định type HPV.

Bệnh viện Bệnh Nhiệt đới Trung ương: làm xét nghiệm giải trình tự gen.

\section{Phương pháp}

Sàng lọc 104 bệnh nhân thì xác định được 63 bệnh nhân nhân có nhiễm đơn HPV 16 và HPV 18, chúng tôi đã tiến hành khảo sát trình tự gen HPV của 63 bệnh nhân này.

\section{Quy trình:}

Bước 1: Bệnh nhân đến khám sàng lọc ung thư cổ tử cung tại Bệnh viện Phụ sản Trung ương được xét nghiệm tế bào nhúng dịch (ThinPrep Pap Test) và HPV DNA.

Bước 2: Chọn những bệnh nhân ung thư cổ tử cung có kết quả HPV (+) đưa vào nghiên cứu. Xét nghiệm DNA - HPV bằng hệ thống Cobas 4800 của hãng Roche nhằm phát hiện HPV type nguy cơ cao: type 16, 18 và 12 type nguy cơ cao khác $(31,33,35,39,45,51,52$, $56,58,59,66,68)$.

Bước 3: Mẫu bệnh phẩm làm xét nghiệm HPV của các bệnh nhân có HPV DNA type $16(+), 18(+)$ được làm xét nghiệm giải trình gen để xác định sự biến đổi nucleotide các gen E6, E7, L1.

\section{Các bước tiến hành giải trình tự gen}

Tách ADN của HPV: sử dụng bộ kit QiaAMP DNA Mini Kit, thực hiện theo hướng dẫn của nhà sản xuất.

Qui trình PCR nhân dòng, giải trình tụ gen tìm đột biến gen L1, E6 và E7

+ Primers (mồi)

\begin{tabular}{ccc}
\hline Gen đích & Tên mồi & Trình tụ̣ \\
\hline \multirow{2}{*}{$16-$ L1, E6, E7 } & 16 L1-E7 F & 5-TAATATAACTGACCAAGCTCCTTCATTAATTC-3' \\
\cline { 2 - 3 } & 16 L1-E7 R & 5'TACATAAAACCATCCATTACATCCCGTACC-3 \\
\hline
\end{tabular}




\begin{tabular}{|c|c|c|}
\hline Gen đích & Tên mồi & Trình tụ \\
\hline \multirow{2}{*}{$18-E 6, E 7$} & 18E6/7 F & 5' GGAGTRACCRAAAACGGTYG - 3' \\
\hline & 18E6/7 R & 5' - CCTTCTGRATCAGCCATTGTT - 3' \\
\hline \multirow{4}{*}{$18-\mathrm{L} 1$} & 18L1 F1 & 5'-GTMTCTGCYACGGRGGACAA - 3' \\
\hline & 18L1 R1 & 5'-CACAGCTGCCAGGTGAAGC - 3' \\
\hline & 18L1 F2 & 5' - CTGGATATGGTGCCAYGGRC - 3' \\
\hline & 18L1 R2 & 5'-CTCACYAGGGCGCAACCACAT - 3' \\
\hline
\end{tabular}

+ Thiết bị: Máy PCR ProLex (Applied Biosystem, Mỹ), Máy điện di MuPis (Nhật), máy giải trình tự nucleotide 3130 sequencer (Applied Biosystem, Mỹ).

+ Kỹ thuật

Sử dụng bộ kit Platinum SuperFi II Green PCR Master mix; Với HPV16 theo phương pháp của Qinglong Shang và cộng sự; với HPV18 theo phương pháp của Hui-Hui Xu và cộng sự, thành phần phản ứng của $\mathrm{PCR}$ nhân dòng các đoạn $A D N$ của gen $E 6, E 7$ và $L 1$ bao gồm $0.5 \mu \mathrm{l}$ mồi, 1 X Platinum SuperFi ॥ Green PCR Master Mix Kit và $5 \mu \mathrm{ADN}$ khuôn. Chu trình nhiệt bắt đầu bằng bước kích hoạt HotStarTaq DNA Polymerase ở nhiệt độ $95^{\circ} \mathrm{C}$ trong 15 phút, lặp lại 35 chu kỳ ở nhiệt độ $94^{\circ} \mathrm{C}$ trong 30 giây, $60^{\circ} \mathrm{C}$ (HPV16) và $58^{\circ} \mathrm{C}$ (HPV18) trong 45 giây và $72{ }^{\circ} \mathrm{C}$ trong 1 phút. Sản phẩm PCR sau đó được điện di kiểm tra trên gel agarose $1,5 \%$, tinh sạch sản phẩm $\mathrm{PCR}$ bằng Qiagen PCR purification kit và tiến hành giải

\section{KÊT QUẢ}

\section{1. Đặc điểm chung của các đối tượng tham gia nghiên cứu}

Bảng 1. Đặc điểm của các đối tượng nghiên cứu và tỷ lệ nhiễm HPV

\begin{tabular}{|c|c|c|c|}
\hline \multirow{2}{*}{\multicolumn{2}{|c|}{ Đặc điểm }} & \multicolumn{2}{|c|}{ Ung thư cổ tử cung } \\
\hline & & \multirow{2}{*}{$\begin{array}{c}\mathbf{n}=\mathbf{6 3} \\
07\end{array}$} & \multirow{2}{*}{$\begin{array}{c}100 \% \\
11,1\end{array}$} \\
\hline Nhóm tuổi & $\leq 34$ & & \\
\hline & $35-44$ & 28 & 44,4 \\
\hline
\end{tabular}

trình tự nucleotide sử dụng các cặp mồi thiết kế. Trình tự nucleotide của các gen E6, E7, L1 sau đó được so sánh với các trình tự gốc trên ngân hàng dữ liệu gen GenBank - NCBI. Với HPV 16 mã Genbank: NC 001526.4 và HPV 18 mã GenBank: GQ18180792. Trình tự đoạn gen L1, E6, E7 của các mẫu được so sánh với các gen tương ứng của gen gốc bằng phần mềm ATGC 7.2 (Nhật) để tìm sự khác biệt về trình tự nucleotide.

\section{Xử lý số liệu}

Số liệu được thu thập, nhập và phân tích bằng phần mềm SPSS 22.0.

\section{4. Đạo đức nghiên cứu}

Đề tài đã được Hội đồng Đạo đức của trường Đại học $Y$ Hà Nội chấp thuận theo quyết định số 109/HĐĐĐĐHYHN ngày 30/5/2017. Bệnh nhân hoàn toàn tự nguyện tham gia vào nghiên cứu, các thông tin cá nhân được bảo mật theo quy định. 
Đặc điểm

Ung thư cổ tử cung

\begin{tabular}{ccc}
\cline { 2 - 3 } & $\mathbf{n = 6 3}$ & $\mathbf{1 0 0 \%}$ \\
$45-54$ & 16 & 25,4 \\
$\geq 55$ & 12 & 19,1
\end{tabular}

Tuổi trung bình 44,0 \pm 9,38; Lớn tuổi nhất là 68; nhỏ nhất là 26 tuổi

\begin{tabular}{cccc}
\hline Nơi sống & Thành thị & 43 & 68,3 \\
\hline Nông thôn & 20 & 31,7 \\
\hline Số lần có thai & $0-2$ & 13 & 20,6 \\
\hline Nhiễm HPV & $\geq 3$ & 50 & 79,4 \\
\hline & Type 16 & 46 & 73,0 \\
\hline & Type 18 & 17 & 27,0 \\
\hline
\end{tabular}

Nghiên cứu 63 bệnh nhân cho thấy, tỷ lệ nhiễm HPV nguy cơ cao được mô tả ở bảng 1 . Tuổi trung bình là 40,0 $\pm 9,38$, người nhỏ tuổi nhất là 26 tuổi, lớn tuổi nhất là 68 tuổi. Phân bố theo địa dư, bệnh nhân sống ở thành thị chiếm

\section{Tỷ lệ đột biến gen E6, E7 và L1 của HPV 16}

Bảng 2. Vị trí đột biến của HPV 16

\begin{tabular}{ccccccccccc}
\hline Vị trí (E6) & 1 & 1 & 1 & 2 & 3 & 3 & 3 & 4 & 4 & 4 \\
& 0 & 7 & 7 & 1 & 5 & 7 & 8 & 1 & 3 & 5 \\
\hline Gốc & $\mathrm{G}$ & $\mathrm{A}$ & $\mathrm{T}$ & $\mathrm{C}$ & $\mathrm{G}$ & $\mathrm{A}$ & $\mathrm{A}$ & $\mathrm{A}$ & $\mathrm{T}$ & $\mathrm{C}$ \\
\hline Biến thể & $\mathrm{A}$ & $\mathrm{G}$ & $\mathrm{G} / \mathrm{A}$ & $\mathrm{A}$ & $\mathrm{T}$ & $\mathrm{G}$ & $\mathrm{C}$ & $\mathrm{G}$ & $\mathrm{C}$ & $\mathrm{T}$ \\
\hline $\mathbf{n}$ & 11 & 11 & 34 & 11 & 46 & 5 & 21 & 14 & 16 & 16 \\
\hline \% & 23,9 & 23,9 & 73,8 & 23,9 & 100,0 & 10,9 & 45,7 & 28,3 & 38,8 & 34,8 \\
\hline Vị trí (E7) & 7 & 6 & 3 & 3 & 4 & 5 & 6 & 8 & 1 & 4 \\
& 8 & 6 & 2 & 9 & 9 & 8 & 6 & 4 & 7 & 6 \\
\hline Gốc & $\mathrm{C}$ & $\mathrm{G}$ & $\mathrm{T}$ & $\mathrm{A}$ & $\mathrm{C}$ & $\mathrm{G}$ & $\mathrm{G}$ & $\mathrm{G}$ & $\mathrm{A}$ & $\mathrm{T}$ \\
\hline Biến thể & $\mathrm{T}$ & $\mathrm{A}$ & $\mathrm{C}$ & $\mathrm{G}$ & $\mathrm{A}$ & $\mathrm{T} / \mathrm{A}$ & $\mathrm{A}$ & $\mathrm{G} / \mathrm{T}$ & $\mathrm{C}$ & $\mathrm{C}$ \\
\hline $\mathbf{n}$ & 28 & 17 & 18 & 6 & 16 & 8 & 13 & 13 & 16 & 17 \\
\hline \% & 60,8 & 37,0 & 39,1 & 13,0 & 34,8 & 17,3 & 28,3 & 28,3 & 34,8 & 37,0 \\
\hline
\end{tabular}




\begin{tabular}{ccccccccccc}
\hline & 5 & 5 & 5 & 6 & 6 & 6 & 6 & 6 & 6 & 7 \\
Vị trí (L1) & 6 & 7 & 8 & 2 & 4 & 6 & 7 & 9 & 9 & 0 \\
& 5 & 0 & 3 & 7 & 2 & 5 & 1 & 1 & 5 & 6 \\
& 9 & 4 & 6 & 7 & 6 & 5 & 9 & 0 & 0 & 0 \\
\hline Gốc & $\mathrm{T}$ & $\mathrm{A}$ & $\mathrm{A}$ & $\mathrm{A}$ & $\mathrm{G}$ & $\mathrm{T}$ & $\mathrm{A}$ & $\mathrm{G}$ & $\mathrm{G}$ & $\mathrm{G}$ \\
\hline Biến thể & $\mathrm{C}$ & $\mathrm{G}$ & $\mathrm{G}$ & $\mathrm{G}$ & $\mathrm{A} / \mathrm{T} / \mathrm{R}$ & $\mathrm{C}$ & $\mathrm{G}$ & $\mathrm{T}$ & $\mathrm{T} / \mathrm{C}$ & $\mathrm{A} / \mathrm{T}$ \\
\hline $\mathbf{n}$ & 15 & 23 & 25 & 5 & 17 & 29 & 25 & 27 & 11 & 37 \\
\hline$\%$ & 32,6 & 50,0 & 54,3 & 10,8 & 36,9 & 63,0 & 54,3 & 58,7 & 23,9 & 80,4 \\
\hline
\end{tabular}

Có 13 đột biến nucleotide trên gen E6 được tìm thấy; trong đó đột biến T350G xuất hiện ở cả 46 chủng HPV. Đột biến T178A có tỷ lệ 14/46 và T178G xuất hiên ở 20/46; Đột biến A378G chỉ có mặt ở 5 chủng HPV. Ở gen E7, vị trí có tỷ lệ đột biến cao nhất là C578T với 28/46 (60,9\%) và thấp nhất là đột biến A739G (6/46; 13,0\%). Trên gen $L 1$ có 40 vị trí đột biến được tìm thấy, trong đó đột biến tại vị trí G7060A có tỷ lệ cao nhất, xuất hiện ở $37 / 46$ chủng HPV $(80,4 \%)$.

\section{Tỷ lệ đột biến gen E6, E7 và L1 của HPV 18}

\section{Bảng 3. Vị trí đột biến của HPV 18}

\begin{tabular}{ccccccccccc}
\hline Vị trí (E6) & 1 & 2 & 2 & 2 & 2 & 2 & 4 & 4 & 4 & 4 \\
& 3 & 2 & 4 & 6 & 7 & 8 & 2 & 3 & 3 & 5 \\
\hline Gốc & $\mathrm{C}$ & $\mathrm{T}$ & $\mathrm{T}$ & $\mathrm{T}$ & $\mathrm{G}$ & $\mathrm{A}$ & $\mathrm{C}$ & $\mathrm{A}$ & $\mathrm{T}$ & $\mathrm{C}$ \\
\hline Biến thể & $\mathrm{G}$ & $\mathrm{C} / \mathrm{Y}$ & $\mathrm{G}$ & $\mathrm{G}$ & $\mathrm{T}$ & $\mathrm{G}$ & $\mathrm{T}$ & $\mathrm{G}$ & $\mathrm{C}$ & $\mathrm{A}$ \\
\hline $\mathbf{n}$ & 1 & 2 & 2 & 2 & 2 & 2 & 4 & 2 & 2 & 3 \\
\hline$\%$ & 5,9 & 11,8 & 11,8 & 11,8 & 11,8 & 11,8 & $23, .5$ & 11,8 & 11,8 & 17,6 \\
\hline Vị trí (E7) & 9 & 1 & 3 & 5 & 6 & 4 & 3 & 9 & 9 & 9 \\
& 6 & 7 & 2 & 8 & 5 & 3 & 1 & 0 & 4 & 8 \\
\hline Gốc & $\mathrm{C}$ & $\mathrm{G}$ & $\mathrm{A}$ & $\mathrm{C}$ & $\mathrm{C}$ & $\mathrm{C}$ & $\mathrm{A}$ & $\mathrm{T}$ & $\mathrm{C}$ & $\mathrm{C}$ \\
\hline Biến thể & $\mathrm{T}$ & $\mathrm{T}$ & $\mathrm{G}$ & $\mathrm{T}$ & $\mathrm{A}$ & $\mathrm{T}$ & $\mathrm{G}$ & $\mathrm{C}$ & $\mathrm{T}$ & $\mathrm{T}$ \\
\hline $\mathbf{n}$ & 4 & 7 & 2 & 4 & 5 & 3 & 4 & 5 & 8 & 8 \\
\hline \% & 23,5 & 41,2 & 118 & 23,5 & 29,4 & 17,6 & 23,5 & 28 & 47,1 & 47,1 \\
\hline
\end{tabular}




\begin{tabular}{ccccccccccc}
\hline & 5 & 5 & 5 & 5 & 6 & 6 & 6 & 6 & 6 & 6 \\
Vị trí (L1) & 4 & 5 & 5 & 8 & 0 & 1 & 1 & 3 & 3 & 4 \\
& 6 & 2 & 7 & 7 & 2 & 4 & 7 & 6 & 9 & 0 \\
& 1 & 5 & 3 & 5 & 0 & 3 & 6 & 7 & 7 & 1 \\
\hline Gốc & $\mathrm{A}$ & $\mathrm{A}$ & $\mathrm{A}$ & $\mathrm{C}$ & $\mathrm{G}$ & $\mathrm{G}$ & $\mathrm{A}$ & $\mathrm{G}$ & $\mathrm{A}$ & $\mathrm{A}$ \\
\hline Biến thể & $\mathrm{G}$ & $\mathrm{G}$ & $\mathrm{C}$ & $\mathrm{A}$ & $\mathrm{A}$ & $\mathrm{T} / \mathrm{C}$ & $\mathrm{G} / \mathrm{C}$ & $\mathrm{G} / \mathrm{C}$ & $\mathrm{C}$ & $\mathrm{G}$ \\
\hline $\mathbf{n}$ & 3 & 1 & 1 & 2 & 2 & 2 & 2 & 1 & 1 & 1 \\
\hline$\%$ & 17,6 & 5,9 & 5,9 & 11,8 & 11,8 & 11,8 & 11,8 & 5,9 & 5,9 & 5,9 \\
\hline
\end{tabular}

Gen E6 có 14 đột biến nucleotide, tỷ lệ đột biến cao nhất ở vị trí G532T (7/17; 41,2\%); còn lại các đột biến có tỷ lệ thấp như C123G, T244Y là $1 / 17$ chiếm tỷ lệ $5,9 \%$.Tìm thấy 6 đột biến

\section{BÀN LUẬN}

Trong nghiên cứu của chúng tôi, tuổi trung bình của bệnh nhân là $44,0 \pm 9,38$, nhỏ tuổi nhất là 26 tuổi và lớn tuổi nhất là 68 . Kết quả này khá tương đồng với nghiên cứu của tác giả Đoàn Văn Khương và Lâm Đức Tâm, tuy nhiên lại thấp hơn so với nghiên cứu của Nguyễn Thị Phương Mai. 8,13,14 Tỷ lệ bệnh nhân sống ở thành thị chiếm $68,3 \%$, trong khi tỷ lệ sống ở nông thôn chỉ có $31,7 \%$ ), số liệu này khác biệt với nghiên cứu của tác giả Aanchal Jain và cộng sự tại thực hiện tại Ấn Độ với tỷ lệ bệnh nhân sống ở nông thôn lên tới 78,3\%. ${ }^{11}$ Tỷ lệ bệnh nhân có số lần mang thai $\geq 3$ lần chiếm tới 79,4\% (bảng 1), theo nghiên cứu của tác giả Trương Quang Vinh thì nhóm phụ nữ có trên 5 con mang nguy cơ tổn thương tiền ung thư và ung thư cổ tử cung cao hơn so với phụ nữ có 4 con trở xuống. ${ }^{15}$ Bệnh nhân nhiễm đơn HPV type 16 và HPV 18 trong đó chủ yếu là HPV 16 với $73,0 \%$, tỷ lệ này cũng tương đương hầu hết các nghiên cứu trước đây (Bảng 1). ${ }^{1,2,11,14}$

Qua phân tích tỷ lệ đột biến gen E6, E7 và L1 của HPV 16 (Bảng 2), nghiên cứu của chúng tôi ghi nhận gen E6 HPV type 16 mang 13 đột biến nucleotide. Tác giả Xiangyi Zhe và cộng sự trên gen E7, trong đó tỷ lệ đột biến cao nhất là C894T và C898T (đều là 8/17; 47,1\%). Gen L1 có 24 đột biến, tỷ lệ đột biến cao nhất là G5612T (3/17; 17,6\%).

phát hiện có 14 đột biến trên gen E6 ở những bệnh nhân ung thư cổ tử cung tại Tân Cương, Trung Quốc; vị trí đột biến cao nhất là T350G với $100 \%$, đây là vị trí được các tác giả đều nhắc đến với tỷ lệ khá cao; theo một số nghiên cứu, trong một số cộng đồng dân cư Châu Âu ghi nhận chủ yếu type HPV 16 thuộc dòng $A$ với các biến thể HPV 16 ERU-350T (đột biến ở vị trí -350G) có khả năng tồn tại dai dẳng cao gấp hai lần so với các type khác. Tiếp đến là T178A/G với; $73,8 \%$; thấp nhất là A378G (5/46; 10,9\%). 6,14,16

Trong khi đó gen E7 có 16 vị trí đột biến, vị trí có tần số đột biến cao nhất là C578T (28/46; $60,9 \%$ ) và thấp nhất là đột biến $A 739 G$ với 6/46 chỉ 13,0\%. So với một số tác giả thì số đột biến họ quan sát đều dưới 10 đột biến. ${ }^{16,17}$

Còn trên gen L1 tổng cộng có 40 vị trí đa hình được tìm thấy, trong đó G7060A (37/46; $80,4 \%$ ) là thường xuyên nhất. Hiện các nghiên cứu về gen L1 còn rất ít được quan tâm.

Với HPV 18, các đột biến gen có ở ít vị trí hơn và tần số thấp hơn rất nhiều so với HPV 16. Hiện nay còn ít nghiên cứu về đột biến của 
HPV 18. Như kết quả của Bảng 3, gen E6 có 14 đột biến sai lệch, tần số đột biến cao nhất là G532T (7/17; 41,2\%); còn lại các đột biến thấp nhất là $C 123 G, T 244 Y$ là $1 / 17$ chiếm tỷ lệ 5,9\%; vị trí T220CY có 2 sự thay thế. Trong khi gen $E 7$ chỉ có 6 đột biến, tần số đột biến cao nhất là C894T và C898T (đều là 8/17; 47,1\%). Còn ở gen L1 có 24 đột biến, tần số đột biến cao nhất với G5612T (3/17; 17,6\%). Nghiên cứu của Sara L Arroyo tại Tây Ban trên 1085 mẫu HPV18 ghi nhận có các đột biến C317C,
T251C, A528G, G266A và G374A trên gen E6, C665T, C593T, C640T và T864G trên gen E7. Trên gen L1 có hai đột biến là C6842G và T7592C. ${ }^{6}$ Nghiên cứu của Hui-Hui Xu và cộng sự tại Trung Quốc trên các mẫu HPV 18 cũng ghi nhận 12 loại đột biến trên gen E6, 9 đột biến trên gen E7 và 49 đột biến trên gen L1. ${ }^{7}$ Như vậy thấy rằng các chủng HPV18 gây bệnh tại Việt Nam có sự khác biệt về số đột biến cũng như loại đột biến so với các chủng HPV18 gây bệnh ở một số khu vực trên thế giới.

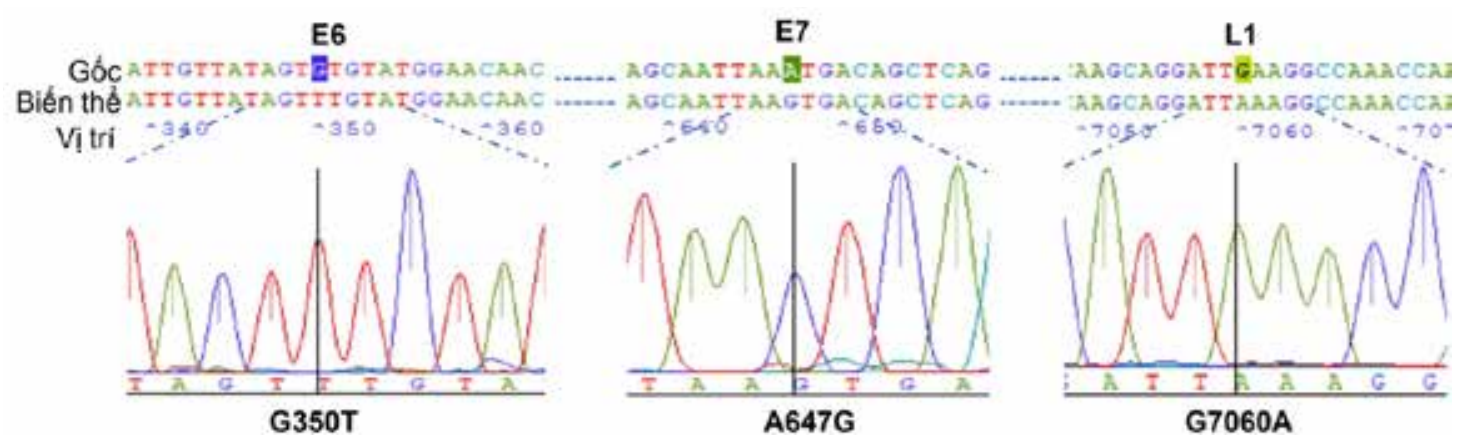

Hình 1. Hình ảnh đột biến 350 G>T (E6), 647 A>G (E7), 7060 G>A (L1) của HPV16

\section{KÉT LUẠN}

Tần suất biến đổi trình tự nucleotide trên gen E6, E7 và L1 của HPV 16 và HPV 18:

HPV 16 ghi nhận có 13 sự biến đổi trình tự nucleotide trên gen $E 6$ và $E 7$, trên gen $L 1$ có tới 40 đột biến.

HPV 18 có 14 đột biến trên gen E6, 6 đột biến trên gen $E 7$ và 24 đột biến trên gen L1.

Tỷ lệ và chủng loại đột biến của các chủng HPV 16, 18 gây bệnh tại Việt Nam có sự khác biệt với các chủng HPV 16, 18 gây bệnh trên thế giới.

\section{LỜ'I CẢM O'N}

Nhóm nghiên cứu trân trọng cảm ơn Bệnh viện Phụ Sản Trung ương, Khoa xét nghiệm Bệnh viện Bệnh nhiệt đới Trung ương đã giúp cho đề tài được thực hiện.

\section{TÀI LIẸU THAM KHẢO}

1. H. zur Hausen, Papillomaviruses in the causation of human cancers - a brief historical account, Virology. 2009; 384(2): 260-265.

2. Iancu IV, Anton G, Botezatu A, Huica I, Nastase A, Socolov DG, et al. LINC01101 and LINC00277 expression levels as novel factors in HPVinduced cervical neoplasia. J Cell Mol Med. 2017; 21(12): 3787-94.

3. Zhao JW, Fang F, Guo Y, et al. HPV16 integration probably contributes to cervical oncogenesis through interrupting tumor suppressor genes and inducing chromosome instability. J Exp Clin Cancer Res. 2016; 35(1): 180.

4. Yang Y, Ren J, Zhang Q. Distribution of human papilloma virus type 16 E6/ E7 gene 
mutation in cervical precancer or cancer: a case control study in Guizhou Province, China. J Med Virol. 2016; 88(2): 345-50.

5. Song D, Shi Q, Hou X, Zhenghai MA. The effect of mutations in the upstream regulatory region of HPV-16 on the activity of virus early promoter. China Oncol. 2017; 27(2): 109-14.

6. Arroyo SL, Basaras M, Arrese E, et al. Human papillomavirus (HPV) genotype 18 variants in patients with clinical manifestations of HPV related infections in Bilbao, Spain. Virol J. 2012; 9: 258.

7. Xu HH, Zheng LZ, Lin AF, Dong SS, Chai ZY, Yan WH. Human papillomavirus (HPV) 18 genetic variants and cervical cancer risk in Taizhou area, China. Gene. 2018; 647: 192197.

8. Doan Van Khuong, Nguyen Vuong (2017). Histologycal pattern and servival time after treatment forr uterine adenocarcinoma. Vietnam Journal of Oncology. 1: 150-56.

9. Lopera EA, Baena A, Florez V, Montiel J, Duque C, Ramirez T, et al. Unexpected inverse correlation between Native American ancestry and Asian Zhe et al. Cancer Cell Int (2019) 19: 65 Page 11 of 11

10. M. Cui, N. Chan, M. Liu, K. Thai, J. Malaczynska, I. Singh, D. Zhang, and F. Ye, "Clinical performance of roche Cobas 4800 HPV test," J. Clin. Microbiol. 2014; 52(6): 2210 2211.

11. Aanchal Jain, Balasubramaniam Ganesh, Saurabh C Bobdey, Jignasa A Sathwara, and Sushma Saoba (2017), Sociological and clinical profile of cervical cancer patient visiting a tertiary care hospital in India.

12. L. T. H. Vu and H. T. T. Le, "Cervical Human Papilloma Virus Infection among the General Female Population in Vietnam: A Situation Analysis,". 2011; 12: 561-566.

13. Lam Duc Tam, Tran Ngoc Dung, Nguyen Vu Quoc Huy (2016). Evaluate the results of treatment of cervical lesions by cryotherapy in Can Tho. Hue University, University of Medicine and Pharmacy Journal of Obstetyrics and Gynecology. 13(4): 52-57.

14. Nguyen Thi Phuong Mai, Pham Van Thuc, Pham Van Han, Nguyen Hung Cuong, Pham Thi Thanh Huyen, Hiroshi Ichimura, Ta Thanh Van (2015). Variants E6, E7 of Human papillomavirus 16 in cevical cancer patients in the North, Vietnam. Journal of Practical Medecine. 966: 423-426.

15. T. Q. Vinh, C. N. Thanh, (2010), Study on Human papiloma vius infection in women with precancerous lesions and cervical cancer, Journal of Practical Medicine, Ministry of Health. 718-719: 229-240.

16. Xiangyi Zhe, Dongdong Cao, Ying Li, Chunhe Zhang, Shaowei Fu, Renfu Shao and Zemin Pan, Genetic variations in E6, E7 and the long control region of human papillomavirus type 16 among patients with cervical lesions in Xinjiang, China (2019).

17. Wu LX, Yun LI, Mu LI, Li FX, Cui MY, Yang $Y$, et al. The expression and clinical significance of Sox 11 in cervical carcinogenesis. J Xi'an Jiaotong Univ MedicalSciences). 2018; 39(1): 73-7. 2013; 11(1): 19-30. 


\section{Summary}

\section{IDENTIFICATION OF NUCLEOTIDE VARIANTS IN E6, E7 AND L1 GENES OF HUMAN PAPILLOMAVIRUS TYPE 16 AND 18 IN CERVIRAL CANCER PATIENTS}

Types 16 and 18 of human papillomavirus have a very high rate of causing cervical cancer. Studies show that mutations in the nucleotide sequence in the genome of types 16 and 18 can promote cervical cancer progression and other symptoms in patients. In this study, we analyzed changes in nucleotide sequences of genes E6, E7 and L1 of two HPV types 16 and 18 in patients with confirmed cervical cancer. 104 patients were screened to include 63 patients in the study of which 46 cases are HPV-16 single infection and 17 cases are HPV-18 single infection. The results of nucleotide sequence analysis of the E6, E7, L1 genes of these types showed that Type HPV 16 has 13 mutations found in the E6 gene; the highest mutation rate was T350G at $100 \%$, the lowest is A378G at $10.9 \%$. C578T site of the E7 gene had the highest mutation rate at $60.9 \%$ and the lowest was A739G at $13.0 \%$. 40 mutations were identified in the L1 gene, of which the G7060A mutation had the highest rate of $80.4 \%$. In HPV Type 18, there are 14 mutations in the E6 gene, the highest rate was G532T at 41.2\%; On the E7 gene, 6 mutations were found, of which mutations C894T and C898T accounted for $47.1 \%$. There were 24 mutations found in the $\mathrm{L} 1$ gene, the highest mutation appeared at position G5612T at $17.6 \%$.

Keywords: Cervical cancer, HPV, mutations, genes E6, E7, L1. 